\title{
0 Desporto como Anatomia do Futuro (Elogio do Professor Nuno Grande)
}

\author{
Paulo Cunha e Silva
}

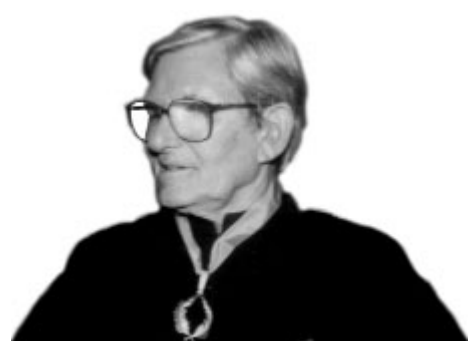

Quando os Professores Jorge Bento e António Marques me convidaram para fazer o elogio do Professor Nuno Grande, no âmbito da homenagem que a FCDEF lhe presta a propósito da sua jubilação, confesso que a minha primeira tentativa foi a de mergulhar no seu currículo e detectar um conjunto de intervenções e de aspectos-chave capazes de, de uma forma impressionista, proporcionarem um retrato que eu desejaria pertinente mas que seria, necessariamente, tosco e incompleto. Esta tarefa, à partida fácil na medida em que se confinava à moldura do seu currículo, revelar-se-ia, pelos mesmos motivos, de uma dificuldade abissal. O seu currículo tem, como todos sabemos, a profundidade da Fossa das Marianas. O risco de, mesmo utilizando o meu batiscafo pessoal, não ter luz suficiente para a essa profundidade distinguir as formas pregnantes, isto é, o que interessa, era muito grande.

Abandonando a ideia do retrato, decidi-me por uma paisagem. Uma paisagem com uma geometria variável que pudesse funcionar como um mosaico fluido, uma paisagem fractal. Ou seja, uma paisagem sem escala. Construindo uma paisagem sem escala, permitiria que os múltiplos heterónimos de Nuno Grande surgissem na sua configuração habitual e, mantendo-me no registo plástico, poderia ainda piscar os olhos a Abel Salazar, seu mestre em termos de intervenção cívica, científica e cultural e, nesse sentido, meu metamestre, o mestre do meu mestre. De facto, formalmente, Nuno Grande foi meu mestre. Fui seu aluno de anatomia no ICBAS e seu assistente na FCDEF, mas também de facto, formalmente, o discípulo formal que fui pode hoje ser considerado um traidor: o assistente de Anatomia virou professor de Pensamento Contemporâneo. Se uma aná- lise superficial legitima esta história de uma traição, uma análise mais atenta diz o contrário. Estou hoje convencido que o Professor Nuno Grande sempre foi meu professor de Pensamento Contemporâneo. Porque, para lá do fulgurante professor, que transformava a aula num momento único de comunicação, de tal forma que aquela que era por definição a cadeira menos comunicativa de um curso de Medicina ou Ciências do Desporto se transformava, num passe de mágica, em campeã absoluta de audiências, para lá desse professor-total, havia uma inteligência cintilante que fazia da disciplina do cadáver uma arte do vivo. O sortilégio da vida. A Anatomia de Nuno Grande era uma disciplina do olhar, um método de dissecação da realidade. A sua lição de anatomia era uma lição de vida. O seu teatro anatómico era o mundo contemporâneo. A possibilidade de pensar o mundo e intervir sobre ele. Com um mestre desta natureza nada mais natural que um discípulo que passasse a olhar o corpo como um território de acelerações e inscrições múltiplas. O corpo passaria a ser para mim, e o culpado era Nuno Grande, o lugar onde a Anatomia e o Pensamento se cruzam. Ou melhor, o lugar onde o pensamento da Anatomia se cruza com a anatomia do Pensamento. É por isso que hoje continuo a sentir-me seu discípulo de Anatomia e continuo a senti-lo como meu professor de Pensamento. Continuo a sentir que um pensamento morfológico da realidade centrado no corpo é absolutamente essencial na compreensão do mundo contemporâneo.

O pensamento morfológico é o pensamento da diferença e a Anatomia Normal é a anatomia da variação. A anatomia da variação é a anatomia da vida. Estou convencido que a minha aproximação ao caos do 
corpo, ao corpo de instabilidades que a gestão da relação norma-desvio precipita, começou nas aulas de Anatomia. O Professor Nuno Grande não descrevia um coração, descrevia corações. E o que são corações senão variações em torno de um tema? Foi com Nuno Grande que aprendi que, apesar de todos termos coração, todos temos corações diferentes. E que, mesmo para cada um, o seu coração, que no imaginário colectivo é o órgão mais regular, a máquina, a batida precisa, é a fonte da maior irregularidade biológica. Além de todos os corações serem diferentes, cada coração bate sempre de forma diferente (apesar de ser possível encontrar um padrão de diferença). A questão já não é a do desvio da norma, mas a da norma do desvio. A norma não existe: ninguém tem uma anatomia normal. A Anatomia Normal é a anatomia daquilo a que temos chamado as variantes possíveis. Foi por isso que nas aulas de Nuno Grande aprendi implicitamente o que era um "atractor estranho", figura que mais tarde usei sistematicamente para tentar perceber e explicar a pulsão que o corpo experimenta entre dissolução e fixação, entre variabilidade e permanência, entre divergência e convergência. Foi assim, nas aulas de Nuno Grande, que fiz de uma forma sistemática (a disciplina chama-se Anatomia Sistemática), a minha introdução ao Pensamento Contemporâneo.

Mas regressemos atrás, a um personagem que suspendi propositadamente nesta narrativa que tem qualquer coisa de confessional e expiatório: Abel Salazar. Abel Salazar deu nome ao Instituto que Nuno Grande fundou. Ao nomearmos qualquer coisa estamos a definir a sua moldura identitária. Um nome é uma janela com vista para uma paisagem (volto a tecer o elo da paisagem). E a paisagem que este nome anuncia é aquela que eu vi quando aos 17 anos aí entrei pela primeira vez. Num grande rectângulo do átrio do ICBAS estava escrita essa frase que talvez tenha levado demasiado à letra: "Um médico que só sabe medicina, nem medicina sabe". Este aforismo, que acabou por funcionar como uma metonímia do próprio Abel Salazar, era também a janela que configurava o mundo de Nuno Grande: o clínico argutíssimo, o professor fulgurante e o investigador lubrificado (uma brincadeira com GEL - Grupo Europeu dos Linfáticos - de que ele foi um impor- tante dinamizador) era alguém que sabia muito mais que medicina. Era um Cidadão no Mundo. Alguém que nunca descalçou as luvas da cidadania, alguém para quem a intervenção cívica não era um direito mas, sobretudo, um dever. Intervenção que não enjeita a possibilidade de descer do pedestal senatorial que naturalmente conquistou (Nuno Grande é hoje um dos poucos senadores do país com direito ao título) e partir para a luta. A luta das ideias e a luta pelos direitos, pela única utopia que vale a pena, a de um mundo melhor. Assim se passou quando foi Mandatário Nacional da Candidatura de Maria de Lurdes Pintassilgo à Presidência da República. Aqui a sua intervenção cívica foi claramente política no sentido nobre do termo, ou seja, a proposta de uma metodologia de intervenção para mudar o estado das coisas. É por isso que hoje, mais do que nunca, essa sua ética da intervenção (que é também uma estética dado o bom gosto e a elegância do seu método), faz sentido. Hoje quando toda a opinião pública e publicada é consensual no aspecto de que nunca o país bateu tão fundo, nunca o pântano foi tão pantanoso, o seu pensamento cívico faz mais sentido do que alguma vez .

Aproveitando essa característica de resistência proactiva à situação através da intervenção cívica regresso a Abel Salazar para dizer que um dos momentos mais estimulantes do nosso trabalho na procura de um pensamento morfológico, de um pensamento que procura as suas formas e quer acção, aconteceu quando, integrando a Comissão de Coordenação das Comemorações do Centenário do Nascimento Abel Salazar, a convite de Nuno Grande, propusemos o projecto "As Cores do Corpo/O Corpo e os seus Discursos" para a Fundação de Serralves, em 1990. Pensava-se o corpo através dos seus múltiplos discursos, naquele que foi o debate mais tranversal realizado em Portugal sobre o assunto (só equiparável ao projecto Anatomias Contemporâneas realizado na Fundição de Oeiras em 1998), e no qual a FCDEF participou activamente, e mostrava-se o corpo, através da sua intimidade histológica na Capela de Serralves. Comemoravam-se assim três variações desse corpo plural que foi Abel Salazar - o pensador, o histologista, e o artista plástico - numa coreografia curiosa em que a máscara mudava de actor. O Abel 
Salazar artista plástico era comemorado através do Abel Salazar histologista.

É esta capacidade de circulação, este desejo de mobilidade pelos vários níveis do saber, esta angústia da incompletude perante os problemas pretensamente resolvidos, que marca a personalidade de Nuno Grande, como marcou a de Abel Salazar. De certa forma, eles são faróis, faróis que cartografam o presente, o seu presente, fornecendo dados fundamentais para uma circulação atenta e segura, mas também faróis que iluminam o futuro. São, por isso, pós-contemporâneos, ou seja, contemporâneos de quem lhes sucedeu ou sucederá, na medida em que possuem essa capacidade prospectiva. De exportarem o seu presente para o futuro e de importarem o futuro para o nosso presente.

O futuro é, hoje, a chave para se compreender o presente. Em momentos de descontinuidade, de fractura paradigmática (científica, cultural e social) presente e futuro trocam de posição. O futuro precede o presente e o presente póscede o futuro. Daí que, para ultrapassarmos essa ansiedade que decorre do facto de todas as certezas terem ido com o vento e de a realidade se esburacar sob os nossos pés, devamos usar a prospecção como método e o futuro como tema, como objecto.

Creio que estamos no local certo para estudar o futuro. O desporto é hoje o mais paradoxal objecto de consumo. Ele insinua-se pelas múltiplas áreas de fractura da contemporaneidade. Desde a possibilidade, que se julgava utópica, de fabricar um corpo, até aos processos de mediatização-limite, o desporto está presente. Ele e o seu alter-ego, o seu "Outro Lado" na expressão de Jorge Bento, são assim a representação social de um mundo em mudança. Força, Resistência, Velocidade, Flexibilidade, Coordenação, os territórios do treino, portanto os argumentos do corpo-treinado, parecem também os apetrechos necessários para enfrentar o futuro, numa sintomática passagem de testemunho entre dois tempos. $\mathrm{O}$ treino é a utopia de um corpo-melhor, portanto de um futuro melhor, e as características que enunciei, parecem quatro das Seis Propostas de Italo Calvino para o Próximo (já este) Milénio.

A afinidade electiva do desporto pelos territórios onde se fabrica o futuro, obriga as Ciências do Desporto, enquanto sistema metodológico que o aborda e estuda, a serem Ciências do Futuro, isto é, Ciências sobre o futuro. Se estávamos no lugar certo, penso que estamos também na hora certa, pois é no momento em que a Faculdade discute o seu futuro que deve tomar consciência que esse talvez seja o seu tema mais pertinente. Como se alguém dissesse: "O que vou fazer no futuro? Vou dedicar-me a estudar o futuro pois essa é a melhor forma de garantir o presente, de garantir que no futuro terei presente!".

Para estudar o futuro, a principal condição é ter curiosidade, a curiosidade contagiante dos Professores Nuno Grande e Ferreira da Silva - que aproveito para celebrar como professor-referência. É permitir que o tal "outro lado" se manifeste. Para que isso aconteça é necessário preservar uma multiplicidade de tendências que, neste caso, nesta casa, vão do mais rígido fundamentalismo científico, estribado num talvez ingénuo, mas seguramente desadequado "publish or perish", ao mais fluido anarquismo metodológico.

É nessa pluralidade metodológica, aparentemente frágil, que reside a nossa força, como se com fios finíssimos que se cruzam oportunamente se tecesse uma malha resistente, uma malha com futuro.

Tentei demonstrar no início deste elogio-tese que a Lição de Anatomia do Professor Nuno Grande era uma lição de democracia, pois era uma lição à volta da variabilidade biológica. Como se a democracia fosse já uma estratégia da Natureza para sobreviver. Uma estratégia anterior à Cultura.

À tentação de um saber autocrático, à tentação de uma perspectiva monotópica do mundo, é necessário responder com a democracia dos saberes. Só assim um mundo poliglota, quase Babel, como as Ciências do Desporto, poderá sobreviver, e com ele essa dimensão prospectiva do desporto, essa capacidade de sondar o futuro. Para isso basta seguirmos a lição de Nuno Grande. Se o fizermos o Desporto revelarse-á uma Anatomia do Futuro. 